\title{
Answer to the comments of the letter "Association between the APOE-E4 allele in Mexican older adults with cognitive impairment"
}

\section{Humberto Nicolini-Sánchez}

Secretaría de Salud, Instituto Nacional de Medicina Genómica, Laboratory of Psychiatric and Neurodegenerative Diseases Genomics, Ciudad de México, Mexico

1. Regarding the comment in the letter to the editor that reads "it is not the first study in the Mexican population analyzing the presence of the APOE- $\varepsilon 4$ allele in cognitive impairment", the source article refers that "for the first time, we have implemented in Mexico a screening program to detect individuals with a high genetic risk of NCD based on the APOE gene isoforms." 1 This is a dynamic program that not only involves $A P O E$ gene genotyping, but also the delivery of results to clinicians and patient follow-up.

Undoubtedly, there are several publications in Mexico assessing the genotype-phenotype-dementia association (MNCD), such as the one by Villalpando Berumen et al. of 2008 ( $n=49$ cases) $)^{2}$ or as the one by Castelli et al. ( $n=48$ cases), where in 2002 this association was considered in people with cognitive impairment in individuals of Spanish origin residing in Mexico. ${ }^{3}$
2. Regarding the comment that "the study population with major neurocognitive disorder is not categorized or stratified with probability diagnoses for the different types of dementia", it should be mentioned that, as indicated in the methodology section, most participants had an Alzheimer-type MNCD diagnosis; however, since the purpose of the work was to make the risk factor public, stratifying the study population ( $n=297$ cases) was not contemplated.

\section{References}

1. Genis-Mendoza AD, Martínez-Magaña JJ, Bojórquez C, Téllez-Martínez JA, Jiménez-Genchi J, Roche A, et al. Programa de detección del alelo APOE-E4 en adultos mayores mexicanos con deterioro cognitivo. Gac Med Mex. 2018;154:555-560.

2. Villalpando-Berumen JM, Mejía-Arango S, Aguilar-Salinas CA, Ordóñez-Sánchez ML, Gutiérrez-Robledo LM. Apolipoprotein E epsilon4, Alzheimer's disease, and cognitive performance in elderly Mexican mestizos. J Am Geriatric Soc. 2008;56:677-682.

3. Castelli P, Sosa AL, Campillo C, Nicolini H, Cruz-Fuentes C. Apolipoprotein $\mathrm{E}$ genotypes in a group of elderly subjects of Spanish descent living in Mexico City. Int Psychogeriatr. 2002;14(3):291-300.
Gac Med Mex. 2019;155:105-105

Contents available at PubMed www.gacetamedicademexico.com 